\title{
'We Have No Hope for Anything': Exploring Interconnected Economic, Social and Environmental Risks to Adolescents in Lebanon
}

\author{
Megan Devonald *, Nicola Jones and Sally Youssef
}

Citation: Devonald, M.; Jones, N.; Youssef, S. 'We Have No Hope for Anything': Exploring Interconnected Economic, Social and Environmental Risks to Adolescents in Lebanon. Sustainability 2022, 14, 2001. https:// doi.org/10.3390/su14042001

Academic Editors: Carlos Salavera and Khadija Mitu

Received: 30 November 2021

Accepted: 7 February 2022

Published: 10 February 2022

Publisher's Note: MDPI stays neutral with regard to jurisdictional claims in published maps and institutional affiliations.

Copyright: (C) 2022 by the authors. Licensee MDPI, Basel, Switzerland. This article is an open access article distributed under the terms and conditions of the Creative Commons Attribution (CC BY) license (https:// creativecommons.org/licenses/by/ $4.0 /)$.
Gender and Adolescence: Global Evidence (GAGE), Overseas Development Institute, London SE1 8NJ, UK; n.jones@odi.org.uk (N.J.); s.youssef.gage@odi.org (S.Y.)

* Correspondence: m.devonald.gage@odi.org.uk

\begin{abstract}
Sustainable development is an effort to balance social progress with environmental equilibrium and economic growth. Young people affected by forced displacement are particularly vulnerable to the economic, environmental and social challenges of their surroundings. Using a framework that centres sustainable development on these three interconnected pillars, this article explores how the economic and environmental contexts in Lebanon impact adolescents' and youth social development, drawing on qualitative data from adolescents in refugee and host community settings. The article highlights that adolescents face economic challenges because of the national economic crisis, exacerbated by COVID-19 lockdowns and service closures, poor labour market opportunities for youth - and for refugees in particular-and rising living costs. The environmental challenges facing adolescents include inadequate shelter (especially in collective shelters and informal tented shelters) and inadequate water, sanitation and hygiene (WASH) facilities. These economic and environmental conditions in turn influence adolescents' social capabilities such as their physical and mental health, and voice and agency. The article concludes by highlighting the need for a more integrated approach to sustainable development that will allow both present and future generations in Lebanon to meet their own needs and live empowered lives. It outlines measures that could help achieve this approach, including: creating policies and programmes that promote investment in technical and soft skills-building to equip young people with the skills they need to take up jobs within the green economy; investing in adolescent-friendly social protection with linkages to environmental projects; and improved shelter, health and WASH facilities, particularly in response to the ongoing and future impacts of climate change.
\end{abstract}

Keywords: sustainable development; adolescents; refugees; climate change; Lebanon; economic crisis

\section{Introduction}

The 2030 Agenda for Sustainable Development has outlined a plan of action for 'people, planet and prosperity'. The Sustainable Development Goals (SDGs) aim to balance all three components of sustainable development: the economic, social and environmental [1], in line with the Brundtland Commission's definition of sustainable development as "development that meets the needs of the present without compromising the ability of future generations to meet their own needs" [2] (p. 41). Striking a balance, however, between these three dimensions is not always simple and conflicts can occur-for example, increasing agricultural production to tackle food security (the social dimension) can cause deforestation (the environmental dimension). In recognition of growing global concerns around the widespread risks of climate change, in October 2021 the United Nations (UN) recognised, for the first time, access to a healthy and sustainable environment as a universal right [3].

Refugees and young people face heightened inequalities and are particularly at risk of disadvantage within each of these three dimensions. Adolescents affected by forced dis- 
placement in the Middle East and North Africa (MENA) region-which hosts 8.95 million refugees [4] - are highly vulnerable to economic, environmental and social challenges, due to exclusion from job markets, limited access to adequate shelter and WASH facilities, and challenges in water scarcity, among others [5-7]. In order to explore the challenges facing adolescents in securing their rights to sustainable development, this paper focuses on the case of Lebanon - a country that hosts the highest per capita proportion of refugees globally (1.35 million refugees out of a population of 6.8 million) [8]. Both refugee adolescents and vulnerable Lebanese adolescents living in Lebanon face significant challenges, such as a lack of access to quality education and protective environments, high rates of child labour and an inability to meet their basic needs [9]. While there has been some attention to the social and economic aspects of adolescents' lives in the MENA region [10-13], we found a lack of literature on the environmental challenges they face. This article addresses this gap and explores how the economic and environmental contexts of Lebanon impact refugee and Lebanese adolescents' social development. We start with a review of the current literature on adolescents' economic, environmental and social contexts in Lebanon, followed by an overview of the conceptual framing, sample and methodology. We then present our findings on the economic, environmental and social challenges facing Palestinian and Syrian refugees in Lebanon as well as Lebanese adolescents among host communities, and the interactions between these groups. We conclude by discussing the implications of our findings for policy and programming in order to support adolescents' development across each of the three dimensions of sustainable development.

\section{Literature Review}

\subsection{Interactions between Economic, Social and Environmental Sustainability}

The interlinkages between economic, social and environmental development are complex. The economic and environmental contexts that adolescents live in can largely influence their social context, including their quality of life, physical and mental health, and levels of inequality. The 2019 Human Development Report highlighted that climate change is both a driver and an outcome of inequality [14]. There is strong evidence for the link between mental health and economic challenges such as unemployment, falling incomes and debt [15-17]. Economic recession is also linked to wider health impacts, with a study in Brazil finding that an increase in unemployment due to the recession was linked to an increase in mortality [18]. Conversely, economic growth has been shown to have positive impacts on infant and child mortality in South Africa [19].

However, economic growth does not always translate into better social development outcomes. Gross domestic product (GDP) has been heavily criticised for not accurately depicting the social and environmental aspects of development, making it an incomplete measure of progress [20]. Increases in GDP only appear to increase quality of life up to a point, and beyond this, the increases begin to produce negative social consequences such as increased income inequality, and reductions in social cohesion and healthy relationships, among other negative consequences [20]. Furthermore, there are strong concerns over the contradiction between environmental sustainability and economic growth [21] and an acknowledgement that a focus on economic growth and consumption is inconsistent with ecological sustainability. As such, alternative measures have been put forward such as the Genuine Progress Indicator (GPI), which builds on GDP but takes into account social and environmental capital by making deductions based on outcomes such as income inequality and environmental destruction [20]. Additionally, the United Nations Development Programme's (UNDP) Human Development Index, which measures three dimensions-long and healthy life (life expectancy at birth), knowledge (expected years of schooling and mean years of schooling) and decent standard of living (gross national income (GNI) per capita) — focuses on people and their capabilities and not economic growth alone. [22].

The capability approach - coined by Amartya Sen $[23,24]$ and further developed by scholars such as Nussbaum [25] and Kabeer [26] —argues against the idea that economic growth (in the form of GDP) is an adequate measure of quality of life. Instead, this 
multidimensional approach focuses on creating an enabling environment where people have the freedom to 'do and be' in ways that they value. This approach recognises the importance of a broad range of capabilities that support many aspects of development, with material wealth perceived as only one aspect of well-being and not an end goal in itself.

In general, pursuing the social components of sustainable development (such as reducing poverty, SDG 1, and inequality, SDG 10) is often associated with higher environmental impacts [27]. It is argued that low-income countries should pay more attention to achieving the social components [28], as high-income countries have greater leverage (and responsibility given that the majority of emissions are caused by high-income countries [29]) to tackle the environmental components of sustainability [26,27]; however, low-income countries are disproportionately impacted by environmental challenges such as climate change $[5,30,31]$ and so it is important that mitigation efforts are a key priority alongside economic and social progress.

One of the unintended consequences of the COVID-19 pandemic has been a deprioritisation of many SDGs, with the economic impacts of the pandemic diverting attention away from the current climate crisis; however, the pandemic recovery process could present an opportunity to rebuild new systems that support adolescents to develop their full capabilities and ensure that all three components of sustainable development are met [32].

\subsection{Lebanon Context}

Lebanon has faced multiple and overlapping shocks in recent years due to substantial financial and political turmoil compounded by the recent Beirut port explosion and the COVID-19 pandemic [33]. Since the 2019 economic crisis, Lebanon has faced a drastic financial meltdown. As a result, in 2020 Lebanon's GDP fell by $20 \%$ and food inflation averaged at $254 \%$ [34]. It was estimated that the extreme poverty rate in Lebanon tripled to $23 \%$ in 2020 (from $8 \%$ in 2019) with this figure estimated to be as high as $90 \%$ for refugee households (up from 55\% in 2019) [35]. Lebanon has a young population; in $202149 \%$ were under the age of 24 [36]. In 2019, national unemployment rates for youth aged $15-24$ years reached $17 \%$ and rates are much higher for other nationalities ( $45 \%$ for Syrians, $36 \%$ for Palestinian refugees in Lebanon, and $57 \%$ for Palestinians from Syria living in Lebanon) [37,38], while youth labour force participation was 30\% at a national level in 2019 [39].

Further challenges ensued from the collapse of the electricity grid [40]. There has been a resurgence of sectarian violence and, in October 2021, Lebanon experienced the worst day of sectarian violence in Beirut in more than a decade [41].

On top of these severe economic challenges, growing environmental issues present further challenges for Lebanon. Pollution levels in Lebanon are high-three times the recommended maximum level-and the World Health Organization (WHO) considers the air quality in Lebanon to be moderately unsafe [42]. Lebanon has also faced a waste and garbage crisis due to the lack of a comprehensive solid waste management strategy ${ }^{0}$ (In 2018, Lebanon adopted its first law on solid waste management; however, there is a lack of enforcement [43]). The result is that many landfills have reached capacity, leading to the build-up of garbage on Lebanese streets and the burning of garbage, which can cause health problems for nearby residents [43,44]. Countries in the MENA region already face high temperatures, and these are expected to become more extreme as global temperatures rise due to climate change, resulting in problems in agriculture and food security [45]. The region is also one of the most water-scarce in the world (it is home to 12 of the 17 most water-scarce countries in the world) [46]. Analysis by the World Resources Institute found that Lebanon is ranked as having extremely high baseline water stress [46]. This problem is only expected to get worse, with mountain snow cover projected to decrease by $40-70 \%$ by 2050, which will impact vital water sources and lead to further water scarcity [45]. Furthermore, a reduction in water supply and crop yields as a result of climate change will significantly impact the GDP of Middle Eastern countries (with an estimated reduction of $6-14 \%$ of GDP by 2050) [47]. 
In terms of overall well-being, Lebanon ranks as high (0.701) on the Youth Development Index (YDI) [48]. Income inequality is average; the Gini coefficient (a measure of inequality) sits just below the average of 38.4 (31.8) [49]; however, the 2021 Global Gender Gap Index ranks Lebanon relatively low, at 132 out of 156 countries, with particularly low scores on economic participation and opportunity, and political empowerment [50]. Mental health problems are also widespread: one study found that over $50 \%$ of Lebanese adolescents suffer from anxiety and 13\% suffer from depression [51].

Middle Eastern countries have a long history of hosting refugees from a range of countries, including Iraq, Palestine and Syria. Lebanon has seen a dramatic rise in the number of refugees since the 2011 Syrian conflict began, and now hosts the highest proportion of refugees per population size, with 840,929 registered Syrian refugees [52] (The number of unregistered refugees is estimated to be much higher (1.5 million) [52]), 17\% of which are aged 12-17 [53]. Population growth, largely due to the displacement of Syrian refugees, has increased the pressure on water availability and other services in Lebanon $[54,55]$; however, the people who are most vulnerable to economic and environmental challenges are, in most cases, refugees themselves $[5,6,56]$. Refugees living in Lebanon face numerous economic hardships and extremely high rates of poverty [7], while their legal status can render them unable to work legally and exacerbate the high unemployment rates [57]. Syrian refugees tend to live in host communities or informal tented settlements (ITS) throughout the country, as the Lebanese government has not allowed the United Nations Refugee Agency (UNHCR) to establish refugee camps for Syrians [58]. Living conditions for refugees are often extremely poor (a report by UNHCR found that in 2020,58\% of Syrian refugees in Lebanon were living in accommodation that fell below humanitarian standards [59]), with many living in unfinished and overcrowded 'collective shelters' that lack basic amenities $[59,60]$.

There are also around 479,000 Palestinian refugees registered with UNRWA in Lebanon, and around $50 \%$ are under the age of 24 [61,62]. Palestinian refugees, on the other hand, mainly live in one of the 12 formal refugee camps or in informal gatherings adjacent to these camps (of these camps, Ein El Hilweh is the largest, and is home to 54,000 people) $[63,64]$. Camps are generally overcrowded and have seen increasing violence due to the lack of security and policing $[64,65]$. Refugee adolescents are often at greater risk of psychosocial problems due to experiences of violence and exclusion, as well as high levels of uncertainty and economic challenges $[6,10,66]$.

\section{Materials and Methods}

\subsection{Conceptual Framing}

Drawing on Mensah's (2019) framework [1], which centres sustainable development on three interconnected pillars - the environment, economy and society-this article explores the interactions between the economic, environmental and social aspects of sustainable development for adolescent refugees and adolescents in host communities in Lebanon. We define sustainable development using the common Brundtland Commission definition as "development that meets the needs of the present without compromising the ability of future generations to meet their own needs" [2] (p. 41). We take a capability approach towards adolescent well-being, and our analysis focuses on a number of capability domains as outlined in the Gender and Adolescence: Global Evidence (GAGE) conceptual framework [67]. In this article, we focus on four main capabilities: education, psychosocial well-being, health and nutrition, and mobility and safety ${ }^{0}$ (in the GAGE conceptual framework mobility and safety is a subset of the broader voice and agency capability [67]), looking at how they are influenced by adolescents' economic (such as poverty, cost of living, unemployment) and environmental (such as waste disposal, pollution, water access) contexts.

\subsection{Overview of Data Collection, Ethics and Analysis}

The research sample (see Table 1) consisted of qualitative focus group discussions with 86 older adolescent (16-19) and youth (20-25) participants (43 male and 43 female) 
aged $16-25$ years. The sample was purposefully selected from vulnerable host and refugee communities.

Table 1. Research sample.

\begin{tabular}{|c|c|c|c|c|c|c|c|c|c|c|c|c|}
\hline \multirow{3}{*}{$\begin{array}{c}\text { Tool } \\
\text { Community } \\
\text { mapping interviews }\end{array}$} & \multicolumn{2}{|c|}{ Gender } & \multicolumn{3}{|c|}{ Nationality } & \multicolumn{2}{|c|}{ Marital Status } & \multicolumn{2}{|c|}{ School Status } & \multicolumn{2}{|c|}{ Age } & Total \\
\hline & Male & Female & Palestinian & Syrian & Lebanese & Married & Unmarried & In-school & $\begin{array}{l}\text { Out of } \\
\text { school }\end{array}$ & $16-19$ & $20-25$ & \\
\hline & 43 & 43 & 30 & 31 & 25 & 26 & 60 & 30 & 56 & 59 & 27 & 86 \\
\hline
\end{tabular}

Research was conducted with Palestinians in the Ein El Hilweh and Wavel refugee camps in Saida and Baalbek, respectively, with Syrians in collective shelters and informal tented settlements (ITSs), and in host communities in Baalbek, Beqaa Valley with Syrian and Lebanese adolescents and youth, in June and July 2021.

Ethics approval was secured from the Overseas Development Institute Research Ethics Committee. Informed consent was obtained from all participants or, in the case of adolescents under the age of 17 , assent was obtained, and consent was gained from parents and guardians. Any safeguarding issues expressed in the interviews were reported and the participants were directed to suitable service providers.

We used qualitative and participatory methods. The young people were interviewed in focus group discussions (FGDs) using a community mapping exercise where adolescents were asked to draw a visual map of their communities in a group to help us understand the economic, environmental and social challenges that adolescents face. The linked questions in the community mapping exercise explored the spaces in which adolescents live (access to services, infrastructure points such as water, waste collections and electricity, access to green spaces and safety in their communities) and how access to those spaces are affected by environmental and economic challenges, as well as by social norms.

A codebook was informed by the conceptual framework (described above) and through detailed debriefing sessions with the research team. The transcripts were coded using MAXQDA qualitative software by a small team of experienced coders who received tailored training. Once the transcripts were coded, the interviews were analysed thematically, by exporting codes into excel and reviewing coded segments from the entire database to identify patterns in the data. The challenges adolescents face in their economic and environmental contexts and the impact of this on their social capabilities were explored. We looked specifically at similarities and differences by gender, location, marital status and nationality.

\section{Results}

The paper first outlines the findings from qualitative FGDs with refugees and Lebanese adolescents and youth based on the economic and environmental challenges that they face in Lebanon, paying close attention to differences based on nationality, location and gender.

\subsection{Economic and Environmental Challenges}

\subsubsection{Economic Crisis}

As already mentioned, since 2019, Lebanon has been experiencing a severe economic crisis and financial meltdown [34]. Our primary research findings highlight that rising costs of living are causing many challenges for adolescents and their families, who are unable to pay for basic amenities or afford rent. Although the costs of food, medicines and other daily needs are rising, wages remain stagnant. An 18-year-old married Syrian girl explained this context as follows: "Wages are still the same, and they raise prices. Nothing, nothing is enough". A 19-year-old Syrian girl added: "You feel that human beings are the cheapest thing now". Although they are still struggling economically, our findings highlight that Palestinian adolescents in the Ein El Hilweh camp have access to services provided by the United Nations Relief and Works Agency for Palestine Refugees in the Near East (UNRWA), including the provision of free water and electricity, and as a result, Palestinian families 
have more money for other amenities. A 21-year-old Palestinian man explained: "Here, in the camp, we do not pay money for the electricity or the water. Basically, many people here are able to secure their food because they don't pay for water and electricity".

Our findings underscore that house prices are also increasing, making it difficult for families to secure decent living accommodation. An 18-year-old Syrian girl explained: "A house that used to cost 150 to 100, will not be given for less than 400 now". State electricity is intermittent, with frequent power cuts; some adolescents reported having electricity for as little as two hours a day. A 16-year-old Lebanese girl similarly noted: "There was no electricity yesterday. The electricity cut off in the whole street and in houses and it didn't come [back] until the next morning". A minority of families pay for electricity from a private provider, but with prices rising exponentially, this is a significant economic expense, and many families (particularly refugees) are no longer able to afford it. A group of Syrian boys aged 16-22 years in a focus group explained: "We pay 150,000 a month ... on the contrary, the state's electricity is less". Inequality in electricity provision is rife. Many adolescents highlighted that the availability of electricity differs vastly between different areas, due to clans controlling certain areas and preventing electricity from being turned off. A 16-year-old Lebanese girl explained: "The Sharawna area are robbers. And it is prohibited to cut off electricity over there ... They get electricity for $24 \mathrm{~h}$... No-one can dare to open their mouths over there".

Fuel prices are also continuing to rise and petrol shortages have resulted in extremely long queues at petrol stations. A 19-year-old Lebanese boy, in a focus group, commented: "With the dollar crisis, the fuel prices rose, fuel became very expensive" while another boy the same age, in the same group, explained: "If you want to go to the gas station [you need to go] from 5 am till 7.30 am".

Job prospects are also very limited for many adolescents. Those who are in work also reported extremely low wages, particularly for Syrian refugees working in seasonal farm jobs: "The ones who are working in the plains are getting very low daily wages", explained a 20-year-old Syrian woman, "12,000 for five hours only. We cannot even get a pack of legumes for the wages that we get," added an 18-year-old Syrian girl. Others reported being exploited by their employers, as a 20-year-old Lebanese man described: "I work on making beverages, the waiter who takes the orders to tables broke glasses. He [boss] deducted 250,000 from my salary. A cup costs a dollar, he pretended that 200 cups were broken".

As a result of the economic situation, many adolescents aspire to migrate to find work, although only those who have the economic means or family connections are able to migrate safely. For others, their only option is to migrate irregularly, placing their lives at risk. A 20-year-old Lebanese man explained that this is often "the last solution". Youth in Lebanon often face years before finding employment or the means to get married and have children, resulting in a delay in their transition to adulthood, termed "waithood" [68]. A 20year-old Lebanese man emphasised that: "At the beginning, we had dreams of building a house or buying a car, but now we dream of bringing a package of bread to the house". A 21-year-old Lebanese young man similarly highlighted that he fears to have aspirations for his future: "I'd be stupid if I got married and had children".

\subsubsection{Housing and Transport Infrastructure}

Many refugee adolescents in Lebanon live in extremely challenging housing conditions. In particular, Syrian refugees living in collective shelters in Baalbek experience major challenges. Collective shelters consist of old apartment buildings that are unfinished and lack appropriate insulation, ventilation or sewage draining systems. An 18-year-old married Syrian girl explained her situation: "If I knock on the wall, the concrete immediately falls out. All of it is old, and the concrete used in the house is not good". Owners of the collective shelters often refuse to fix the infrastructure issues and are primarily concerned with collecting rent. In the ITSs, Syrian adolescents face similar challenges with their housing infrastructure, as accommodation is often comprised of plastic sheeting and timber 
structures, which provide little protection and are often overcrowded. A 20-year-old Syrian young woman described how: "It's scary during storms and wind ... There are people whose tents had holes in and were torn. We place tyres above them [to fix them]".

In the Palestinian camps, adolescents also face some challenges such as a lack of protection against extreme temperatures due to a lack of electricity and poor infrastructure; however, in general, Palestinian adolescents receive greater support from UNRWA to help them with accommodation. A 20-year-old Palestinian man described the support his family received: "UNRWA funded us to make two bedrooms, a kitchen and a bathroom when they did the house restoration. They gave us $\$ 8000$ ". However, adolescents also reported that there were significant delays in receiving this support and, as a consequence, some families are living in dangerous conditions. As a 20-year-old Palestinian man described: "We started to request seven years ago for them to approve our names ... [it is down to] your luck if your name comes or not".

Although Lebanese adolescents can also face challenges in their living accommodation such as flooding, it is less common than with refugee and, in particular Syrian, adolescents.

Climate change is expected to increase temperatures in Lebanon by between 1.7 and 1.9 degrees Celsius by 2050 [45]. Currently, adolescents' housing provides very limited protection from the increasing temperatures and extreme weather events that will result from climate change. Many refugee adolescents describe how their shelters leak during winter and are extremely hot during summer. In a focus group discussion with Syrian males aged 16-22 years, one explained: "The house does not protect from the heat, it is too hot ... At home, the temperature is higher than when you are standing in the sun". Some adolescents, particularly Lebanese adolescents, are aware of the impact that climate change is having and have noticed increased temperatures in recent years. A 17-year-old Lebanese girl explained: "The pollution and cutting lots of trees is also causing global warming, the temperature is increasing and it's beyond normal, the winter isn't as cold as before". A Palestinian woman, aged 23, added: "The heat is abnormal, we're being grilled"; however, some adolescents (mainly boys) are more sceptical of climate change and do not believe that is it causing the increased temperatures.

The high levels of traffic in the urban areas of Lebanon contribute to an unsafe environment, with large numbers of cars causing extreme levels of both air and noise pollution, as a 17-year-old Syrian girl noted: "In the street you can see car emissions and smoke that cause pollution". Although diesel cars have been banned in Lebanon since 2002 [69], there are many illegal diesel cars in Baalbek as they are much cheaper to run, as a 19-year-old Lebanese boy explained: "We used to pay 5000 when we filled up the car with diesel. I swear, it costs 12,000 with petrol". Roads in general appear to be increasingly unsafe (partly due to increased traffic at gas stations due to the fuel crisis) and are unfavourable for more environmentally friendly methods of transport such as walking or riding a bike. As an 18-year-old Lebanese girl noted: "We used to ride the bicycles as the street would be empty ... Now the street is narrow and there are many accidents due to that".

\subsubsection{Waste Disposal}

Inadequate waste collection and sewage systems are a major problem for many adolescents and result in an extremely polluted surrounding environment. There is also inequality in the garbage collection among neighbourhoods. Waste collection systems are poor, and adolescents report high levels of garbage in the streets, and in rivers and other water sources. The challenging economic situation has exacerbated this, with garbage collectors not being paid and going on strike, as a 19-year-old Lebanese boy explained: "It's a disaster when they go on strike. They all went on a strike in our area. The municipality doesn't have a budget". Furthermore, in ITSs, although there is a garbage collection system in place, it is expensive, so many families burn their garbage instead. A 19-year-old Syrian girl explained: "Garbage is everywhere. People here started saying that they don't want the municipality [to take away garbage]. They burn it instead because of money, [it costs] LBP 10,000 from every tent". In the collective shelters, garbage is also left in the streets or 
burnt, as a 16-year-old Syrian boy described: "There aren't any containers in our neighbourhood ... people just throw their garbage on the street in front their houses ... We have a roundabout near us where people also throw their garbage and it is piled with garbage bags". In Palestinian camps, there appear to be better systems for garbage collection, which is a service provided for free by the UNRWA. As a 21-year-old Palestinian young man explained: "Under each building, people put a basket for garbage. So, when the UNRWA workers come, they take it".

Large landfill sites in Baalbek and near Palestinian camps also cause major environmental concerns. In Baalbek, these sites are controlled by gangs who burn the garbage in order to collect scrap metal. This covers the whole city with ash and causes a high level of pollution, with rancid smells in the surrounding areas. A 16-year-old Lebanese girl explained: "They burn it there every month. The air will be full of smoke and it smells bad. My friend lives next to [the landfill site] ... she doesn't know where to escape when they burn it, the smell is disgusting, they leave the house for two or three days due to the smell".

Although many adolescents complained about this issue, they also highlighted a lack of awareness in the community on recycling and garbage disposal. Some organisations provided houses with bins for sorting garbage, but instead the households would use the bins for other purposes (such as storing food). A 17-year-old Syrian girl explained: "They told us to sort the garbage in the house [but] people would never be committed for sure. People keep the baskets for themselves". Due to the economic crisis, theft of garbage bins is also a common occurrence, particularly in poorer areas that have less security, a 19-year-old Lebanese boy confirming that "they take garbage barrels and sell them".

To try and tackle this problem, some non-governmental organisations (NGOs) are conducting environmental initiatives such as tree planting and cleaning the streets. An 18year-old Lebanese girl commented that: "We worked with the studies centre (the Lebanese Organization for Studies and Training, (LOST)) for 10 days. We cleaned and planted trees along the roads and distributed cans in areas where the garbage containers were stolen". For Palestinian youth, the UNRWA also launched a number of similar initiatives, as a 21-year-old Palestinian young woman explained: "UNRWA launched a drive for the youth to sweep the streets and they were paid for it". Such initiatives have positive economic and environmental effects on adolescents and their communities; however, other adolescents highlighted that there was a lack of follow-up and supervision of those enrolled in such initiatives, and that the NGO activities are seen as only a short-term solution to the lack of support and services from the municipality.

\subsubsection{Water Access and Quality}

Water access is inextricably linked to the electricity challenges in Lebanon, as electricity is required to pump water into the tanks for some households. Consequently, for some families, access to water has become interrupted. A 16-year-old Palestinian girl explained: "When we don't have electricity and there will be no water in the siphon [toilet], we use the pump to fill it from the drinking water in the kitchen". Syrian refugees in the collective shelters are often without water for many days. A 21-year-old Syrian young woman explained: "Even the public water is being cut. The country provides us with water every three or four days". Distance to water sources is also a problem for some adolescents, as many have to travel long distances in cars to obtain water or, in the case of those living in collective shelters, rely on the house owners to collect water for them.

The quality of water is also a problem for all adolescents. Water sources are often near to garbage and sewage and thus risk being polluted. As a result, many families have to buy bottled drinking water, bringing an additional economic expense due to the rising cost of bottled water. A 19-year-old Syrian girl explained: "It [water] contains mud and impurities. That's why we started buying water almost a month ago". A 20-year-old Palestinian young man commented: "They opened the infrastructure and they found that the sewage pipes were damaged and the water was contaminated". 
For Palestinians, affording water is less of a problem, as water is provided for free by the UNRWA; however, access can still be an issue due to power cuts, which means that people are unable to pump the water to fill their tanks, and so the quality of water remains a key challenge.

Adolescents reported that some water sources are drying up. An 18-year-old Lebanese girl explained: "It [drought] happened two years ago. They started buying water, some wells had water, and some didn't, and the wells which had water, they had turbid water, and there was drought, so they started buying water. It didn't rain or snow that year". A 19-year-old Syrian girl described the impact drought has had on agricultural produce: "A huge amount of potato produce was destroyed and huge quantities of vegetables too, in the whole of Lebanon, maybe it is due to the lack of proper rains or the lack of water". Some Lebanese adolescents equate this problem with climate change, as a 21-year-old Lebanese young woman explained: "Due to pollution and the burning of garbage, if they do that a lot, it will affect the weather and cause global warming, and it won't rain much in the winter". Adolescents who are involved in tree planting also highlighted a lack of water as a key problem: "We planted, and not all of them grew as there is lack of water. The tanks don't have enough water to do so, to water them for a proper period of time," explained a 20-year-old Syrian young woman.

\subsection{Social Development Challenges}

The previous section has described the substantial economic and environmental challenges facing adolescents in Lebanon. In this section, we discuss in more detail how these challenges affect adolescents' social development. We focus on four capability domains: education; psychosocial well-being; health, nutrition and sexual and reproductive health; and voice and agency (with a focus on mobility and safety).

\subsubsection{Education}

The challenging economic situation has resulted in a lack of job opportunities for graduates, which has further constrained adolescents' educational aspirations. Many see a diminished value in education, as a 16-year-old Lebanese boy explained: "If a girl who has completed her education in the university is working in a gas station in Beirut, should I complete my education?" High levels of poverty can also make it challenging for some adolescents to fund their education, and there is a lack of scholarships for higher education, as a 17-year-old Palestinian girl highlighted: "I wanted to register in the university in the coming year but I cannot. Firstly, because there is no money".

Access to education is further impacted by the electricity and petrol shortages. The long queues for petrol can result in some adolescents missing their education: A 19-year-old boy explained: "If you want to go and fill the fuel, there won't be any left. We are obliged to leave at 4 am and you will have exam after three hours, but you will lose an hour of that exam just because you have to reach the gas station to fill the tank". Inability to afford transportation is also a major challenge to in-school adolescents, and some even reported stopping their education due to this. A 20-year-old Lebanese young woman stated: "I cannot go to my university, the bus fees have become very high ... If I want to go for two or three days to the university, it will now cost more than my father's salary... I stopped studying and I started looking for jobs to help my family".

With some education moving online due to the COVID-19 pandemic, electricity shortages have made it very difficult for adolescents to access online classes due to a lack of internet connectivity. High temperatures at home also make for an unconducive learning environment, which has impacted learning outcomes for many adolescents, as a 17-year-old Palestinian girl explained: "When I was studying, they used to offer online lessons for us to study before the exams. There was no electricity and Zoom wouldn't open. Due to the heat, I used to sweat a lot, due to that I couldn't memorise. Before the exams, I was crying, I didn't want to appear in the exams, as I wasn't able to do it". 
The lack of electricity also causes a challenging working environment for teachers, who are poorly paid due to a reduction in their salary as a result of the economic crisis. A 21-year-old young man explained: "Our teacher puts a wet towel on his head as there's no electricity. Once he was teaching us inside his car and he put the air conditioner on due to the hot weather. Can you imagine how miserable being a teacher is here in Lebanon?"

\subsubsection{Psychosocial Well-Being}

Adolescents' economic and social environments can also have a negative impact on their psychosocial well-being. Many of the adolescents in our research live in polluted environments due to the lack of garbage disposal and burning of garbage at landfill sites, which is impacting their mental health. A 19-year-old Lebanese boy explained: "He [friend] left his house because of the bad smell, don't these things have psychological effects on you? Of course, one won't be happy by such things". Poor housing infrastructure and frequent power cuts can further impact adolescents' psychosocial well-being. A 20-year-old Palestinian young woman explained: "The weather is very hot, there is no electricity or internet connection. Really, it will give rise to a state of depression. You will feel that you are depressed. You won't have the mood to talk to anyone". This has a particularly strong impact on young married mothers, who face challenging conditions while looking after their young children. One 18-year-old-Syrian girl, a mother, explained: "I face much difficulty. I hate my life until they [my children] sleep ... Yesterday night, the electricity was off, and my husband left me to see a man from Syria. My child started crying, and I didn't know where to go. I felt worn out until the electricity came back".

The polluted environment further impacts adolescents' access to recreational places where they can socialise with their friends. An 18-year-old Lebanese girl explained that she can no longer swim in the river: "We used to swim in the river ... [now you can't] ... it's full of garbage". In general, adolescents highlight a lack of green spaces available to them. On the outskirts of the Palestinian Wavel camp, this has been exacerbated by unregulated house-building, as a 17-year-old boy explained: "We used to hunt in the plain as there were no houses before but now, they build in the plain too ... Many people built in the area. They end greenery, trees have numerous benefits and the noise is annoying". However, within the same focus group discussion, another 19-year-old Palestinian boy mentioned the potential economic benefits of unregulated house-building: "It has some benefits; provides jobs for people in the building," highlighting some of the contradictory economic and environmental impacts. As well as a lack of safe places where adolescents can go to meet their friends, lack of money also prevents them socialising, as a 20-year-old Palestinian young woman described: "You cannot even think of going out due to price inflation. It is better to stay inside your home, get depressed rather than going to the boulevard". High fuel prices further restrict adolescents' mobility. An 18-year-old Lebanese boy stated: "We used to go out every week and sometimes we used to go and explore different areas ... how can we do this now? ... One cannot visit his friends anymore because the fuel would cost a fortune".

The dire economic prospects in Lebanon have resulted in a sense of hopelessness for many adolescents, who are unable to see a positive future. An 18-year-old Syrian girl commented: "We have no hope for anything". The inadequate living conditions have further impacted many people's mental health, as a 16-year-old Lebanese girl explained: "You'll feel that your future is finished, and you'll ask, what are you living for? There are many people who have committed suicide due to the living situation".

\subsubsection{Health and Nutrition}

The economic crisis is also having a significant impact on adolescents' health. Adolescents reported that many households are suffering from food insecurity due to the rising cost of living, and as a result, many adolescents lack a varied diet or have reduced their food intake. An 18-year-old Syrian girl highlighted the challenges facing her family: "Vegetables are really expensive. In the past, we had a choice between what we prefer and 
not prefer. Now, we are forced to eat whatever". Food quality has also decreased. Quite a few adolescents in our sample reported experiencing food poisoning, and many believe that crops are being contaminated with sewage: "The vegetables are being watered by this water, and it's transferring things to us like dirt and diseases," explained an 18-year-old Lebanese girl. The lack of electricity also causes food to spoil due to a lack of refrigeration. A 16-year-old Syrian boy explained: "Whenever you bring vegetables, bring milk, and everything for the fridge, there is no electricity, they all go [off]".

The economic crisis has also meant there is a lack of availability of medicines, and many adolescents and their families are unable to afford healthcare. Many respondents reported that they (or their family members) have had to stop taking their medication because of this. A 19-year-old Syrian girl explained: "We searched in all the pharmacies, only one was open and didn't have the medicine. He said that he doesn't even have Panadol". Additionally, some Syrian refugees feel discriminated against by health services and feel that Lebanese patients are given preferential treatment, as a 19-year-old Syrian girl described: "They discriminate between Syrians and Lebanese ... They let the Lebanese pass before Syrians even if it wasn't necessary".

Menstruation products are also unaffordable for many adolescent girls. Respondents reported having to use tissues, cloths or their children's nappies, or buying cheaper, lowerquality products, which can cause rashes and allergic reactions. A 16-year-old Lebanese girl explained: "I used to buy the private brand pads, they were good quality, but now it is very expensive, so I started looking for the cheaper one. It's not that good, I was used to a better quality than this one and it causes allergies".

The adolescent girls' surrounding environment can also impact their menstruation management due to a lack of privacy. In the ITSs, the toilets are located outside and shared between many families, with men often reported to be sat outside of the toilets, causing girls to change their menstruation products inside the tents. A 20-year-old Syrian young woman explained that: "It's hard for women, it's normal for men. They feel shy as the guys will be sitting outside or if there's someone inside the bathroom". Girls in collective shelters also share bathrooms between many family members and have highlighted the difficulties this causes when they have their period. The lack of water can also impact their ability to wash and maintain good hygiene, which could bring particular problems for girls and young women during menstruation. As a 21-year-old Palestinian young woman explained: "If there is water I will wash, and if there isn't, I don't"; however, social norms surrounding menstruation mean that girls often do not shower during menstruation even when water is available (social norms surrounding menstruation mean that girls often do not shower during menstruation even when water is available).

As noted in the previous section, high levels of air pollution and the practice of burning garbage can aggravate asthma, as an 18-year-old girl noted: "People who have asthma, can't breathe. The house gets full of smoke and fog, the smell too. We close the windows, and the smell is really bad as they burn nylon and bottles of plastic".

Poor infrastructure brings further challenges, due to leaks and flooding, which result in mould and damp, as a 16-year-old Lebanese girl described: "Some people's houses are badly affected by moss and humidity, and remain damp, which causes diseases". As mentioned previously, many adolescents live in housing that does not protect them from the hot weather, and some adolescent parents reported that their children have suffered from dehydration, most likely due to a combination of the hot weather and difficulty accessing water. A 20-year-old Syrian young man explained: "My son had a disease, and I took him to a private doctor to examine him. He was dehydrated, and our neighbour's son is also in the same condition. All the children are the same".

The quality of water is seen as a major issue, as many water sources are thought to be polluted. Many adolescents reported cases of people developing kidney stones, conjunctivitis and stomach problems, as a 20-year-old Palestinian young man noted: "People used to drink water normally and they didn't know that water was mixed with sewage. They got sick". 


\subsubsection{Mobility and Safety}

Due to the economic situation in Lebanon, the frequency of theft and robberies has increased significantly, resulting in a dangerous environment for many adolescents. As a 19-year-old Lebanese boy explained: "The situation isn't good now. As the dollar crisis is worsening, the robberies have increased. They are stealing just anything". This has had an impact on adolescents' mobility, as many reported being too scared to go outside due to the high levels of violence. An 18-year-old Syrian girl explained: "Here, there is only fear and horror. You always hear of people being killed and kidnapped. I don't like to go out because of this". Although it is recognised that this increased violence impacts the mobility of males and females alike (although for males this is mainly at night time), girls face the added challenge of social norms that restrict their mobility due to fears of sexual harassment or kidnapping. A 21-year-old Lebanese young man highlighted this concern: "Even in the daytime, if they [sisters] want to go for a walk, I go with them, you feel afraid and worried about the ones who'll harass her".

There is a lack of policing on the streets of Lebanon, and many adolescent boys and young men have instead resorted to carrying weapons to protect themselves. An 18-yearold Palestinian boy explained: "I have the shotgun with me. I keep it in the bag of the car with me. If the country doesn't protect you, who could?"

Climatic factors can further impact adolescents' mobility due to flooding during the rainy season. Certain areas of Baalbek are flood prone, and there is limited infrastructure to deal with heavy rains, which can make it difficult to move around. This is particularly challenging for adolescents living in ITSs who struggle to leave the house during winter, as an 18-year-old Syrian girl highlighted: "In winter, there are just pits around us. We don't even go out, not even to the bathroom. The ones who work in places [outside the ITS] have to wear plastic bags".

\section{Discussion}

Framed around Mensah's [1] three interconnected pillars of sustainable development (the environment, economy and society), this article has highlighted the interconnecting economic and environmental challenges facing refugee and host community adolescents in Lebanon, and the impact these challenges have on their social capabilities. Lebanon's severe economic crisis has brought a myriad of consequences for adolescents and their families and it has made it difficult for adolescents to develop their capabilities in a number of domains: they cannot afford to meet their daily needs such as food and medicines, and there are very limited job opportunities, which impacts on their educational aspirations, psychosocial well-being and exposure to rising levels of crime. Adolescent girls face particular social challenges due to conservative gender norms, including limitations on their mobility as a result of increasing risks of sexual harassment and an inability to afford menstrual health products.

Poor environmental conditions are closely linked to the economic crisis and have brought further challenges to adolescents' lives. These include unhygienic and dangerous surrounding environments due to limited waste collection systems, pollution and a lack of recreational green spaces. These impact on adolescents' psychosocial well-being, while a lack of access to clean water is contributing to health problems among adolescents. Although these challenges impact both Lebanese and refugee adolescents, Syrian refugees in particular face significant challenges due to their socioeconomic exclusion and challenging living environments. Palestinian refugees also face significant challenges, but support from the UNRWA in waste disposal and water provisions help to mitigate some of these challenges. Climate change is, and will continue to act as, a threat multiplier to the current economic and environmental struggles in Lebanon. The Ministry of Environment has estimated that by 2040, climate change will cause a 14\% fall in Lebanon's GDP [70]. Climate change is expected to increase the temperatures in Lebanon and make water sources even scarcer [71], which will negatively affect agriculture and the health and livelihoods of many people. Despite the current challenges it faces, Lebanon has committed to signifi- 
cant measures to combat climate change and it had announced that it aims to cut carbon emissions by $20 \%$ (up from 15\%) by 2030 [72]; however, our findings indicate that currently, adolescents in Lebanon have limited means to adapt to the impacts of climate change, due to housing infrastructure that provides limited protection to climate-related hazards such as high temperatures and flooding. This problem is especially impacting Syrian refugees living in collective shelters and ITSs. While most of the literature discusses the impact of climate change on displacement $[73,74]$, this article highlights the vulnerabilities to climate change that many refugee adolescents face in their host communities due to intersecting economic and environmental challenges. Health impacts are also notable (due to pollution, rising temperatures and poor water quality). These challenges are only expected to get worse as climate change continues, yet adolescents do not have economic support to help mitigate these health impacts. There is an urgent need for a more integrated approach to sustainable development that will allow both the present and future generations in Lebanon to meet their needs and live empowered lives. Our findings underscore the need for policy and programmes to consider the economic, environmental and social challenges facing adolescents if they are to develop to their full capabilities. When working towards sustainable development, the three interconnecting pillars of sustainability need to be recognised and interventions in one of these pillars should not be implemented in isolation or come at the expense of the others. In this article, we have highlighted the substantial impacts of an unfavourable environment on adolescents' health and psychosocial well-being, which in turn are likely to have life-course spill-over effects. Adolescence is a pivotal life-stage, where very rapid biological and psychosocial development occurs [75]. Therefore, the challenges outlined in this paper-such as problems accessing education, poor nutrition and a lack of recreational spaces - can have significant impacts on adolescents' future trajectories. The broader literature also highlights the impact of environmental factors on adolescent capabilities, where exposure to healthy, green and sustainable environments can have beneficial impacts on adolescents' physical and mental health [76-78], while exposure to pollution can have negative impacts [79-81]. In particular, adolescents and youth in the MENA region have been shown to be vulnerable to the impacts of climate change, which are exacerbating the existing economic challenges such as limited employment prospects, especially for refugee communities [81]. Therefore, it is important that access to a healthy and sustainable environment is integrated as a core component of adolescentand youth-responsive humanitarian and development strategies and action plans.

To support adolescents' realisation of their full capabilities through sustainable development, we suggest that policy makers consider the following measures. These include: (1) promoting investment in technical and soft skills-building to equip young people with the skills they need to take up jobs within the green economy; (2) investing in adolescentand gender-responsive social protection with linkages to environmental projects (such as garbage collection and tree planting); and (3) improving shelter, health and WASH facilities, particularly in response to the potential changes induced by climate change and for refugee communities, and addressing the specific challenges facing girls. Air pollution, which continues to rise to extremely unhealthy levels ${ }^{0}$, (current air pollution figures are unknown due to funding cuts for the Ministry of Environment, which caused air monitoring stations throughout Lebanon to be shut down [82]), also needs to be addressed through revitalising the public transport system, by promoting the use of affordable mini-buses for transport to school and work, investing in renewable energy, particularly solar, and strengthening and subsidising garbage collection systems to discourage the burning of garbage. Finally, more broadly, raising awareness among young people about the importance of sustainable development and environmental protection through schools, community forums and media is also critical in order to strengthen the accountability processes around the governance of environmental policies. 


\section{Conclusions}

This article has outlined the ways in which the multiple and overlapping crises facing Lebanon have drastically impacted young people's lives. Precarious external living environments have been compounded by economic challenges and have had substantial impacts on adolescent and youth social capabilities including education, psychosocial well-being, health and mobility. Over time, there is little doubt that the climate crisis will act as a threat multiplier and will likely result in a worsening of the challenges outlined in this paper. Although both Lebanese and refugee adolescents face significant economic and environmental challenges, the article underscores that Syrian refugees face particular challenges in their living conditions, due to an absence of formal camp infrastructure and a dearth of affordable shelter within host communities, as well as limited access to water and waste services. To support the sustainable development of adolescents and youth affected by forced displacement, all three components of sustainability-economic, environmental and social — need to be comprehensively supported within both humanitarian and development responses.

Author Contributions: Conceptualization, M.D. and N.J.; methodology, S.Y.; formal analysis, M.D. writing—original draft preparation, M.D.; writing—review and editing, N.J. and S.Y.; supervision N.J. All authors have read and agreed to the published version of the manuscript.

Funding: The authors wish to acknowledge that the GAGE programme is funded by the Foreign, Commonwealth and Development Office (FCDO); however, the views and information expressed in this article are not endorsed by the FCDO, which accepts no responsibility for such views or information or any reliance placed on them.

Institutional Review Board Statement: Not applicable.

Data Availability Statement: Not applicable.

Acknowledgments: The authors wish to thank Kathryn O'Neill and Anna Andreoli for their excellent editorial support.

Conflicts of Interest: The authors declare no potential conflict of interest.

\section{References}

1. Mensah, J. Sustainable Development: Meaning, history, principles, pillars, and implications for human action: Literature review. Cogent Soc. Sci. 2019, 5, 1653531. [CrossRef]

2. World Commission on Environment and Development (WCED). Our Common Future; Oxford University Press: New York, NY USA, 1987.

3. United Nations. The Right to a Clean and Healthy Environment: 6 Things You Need to Know; United Nations, 2021. Available online: https:/ / news.un.org/en/story/2021/10/1103082 (accessed on 22 November 2021).

4. World Bank. Refugee Population by Country or Territory of Asylum MENA; World Bank, 2020. Available online: https: / / data.worldbank.org/indicator/SM.POP.REFG?locations=ZQ (accessed on 22 November 2021).

5. $\quad$ Devonald, M.; Jones, N.; Yadete, W. 'The First Thing That I Fear For My Future is Lack of Rain and Drought': Climate Change and its Impacts on Adolescent Capabilities in Low- and Middle-Income Countries; Gender and Adolescence: Global Evidence: London, UK, 2020

6. Jones, N.; Baird, S.; Presler-Marshall, E.; Małachowska, A.; Kilburn, K.; Abu Hamad, B.; Essaid, A.; Amaireh, W.; Sajdi, J.; Banioweda, K.; et al. Adolescent Well-being in Jordan: Exploring Gendered Capabilities, Contexts and Change Strategies. In $A$ Synthesis Report on GAGE Jordan Baseline Findings; Gender and Adolescence: Global Evidence: London, UK, 2019.

7. Presler-Marshall, E.; Jones, N.; Gercama, I. Adolescent Girls in Lebanon: The State of the Evidence; Gender and Adolescence: Global Evidence: London, UK, 2017.

8. Norwegian Refugee Council (NRC). These 10 Countries Receive the Most Refugees. NRC. 2020. Available online: https: //www.nrc.no/perspectives/2020/the-10-countries-that-receive-the-most-refugees (accessed on 22 November 2021).

9. Plan International. Adolescent Girls and Boys Needs in West Bekaa and Mount Lebanon; Plan International: Beirut, Lebanon, 2021.

10. Abu Hamad, B.; Jones, N.; Presler-Marshall, E.; Samuels, F.; Gercama, I. Interrogating the Potential of a "Cash Plus" Approach to Tackle Multidimensional Vulnerability in Humanitarian Contexts: The Case of Syrian Refugees in Jordan. In Social Policy in the Middle East and North Africa: The New Social Protection Paradigm and Universal Coverage; Jawad, R., Jones, N., Messkoub, M., Eds.; Edward Elgar: Cheltenham, UK, 2019.

11. DeJong, J.; Sbeity, F.; Schlecht, J.; Harfouche, M.; Yamout, R.; Fouad, F.M.; Manohar, S.; Robinson, C. Young lives disrupted: Gender and well-being among adolescent Syrian refugees in Lebanon. Confl. Health 2017, 11 (Suppl. 1), 23. [CrossRef] 
12. Youssef, S. There is Nothing Else to Aspire to in Our Life: Exploring the Psychosocial Wellbeing of Married Syrian Refugee Girls in Lebanon. In Adolescents in Humanitarian Crisis: Displacement, Gender and Social Inequalities, 1st ed.; Jones, N., Pincock, K., Abu Hamad, B., Eds.; Routledge: Abingdon, UK, 2021.

13. Abouzeid, M.; Halwani, D.A.; Mokdad, A.H.; Habib, R.R. A Generation at Risk: The Impacts of Lebanon's Escalating Humanitarian Crisis on Children. Front. Public Health 2021, 9, 704678. [CrossRef]

14. UNDP. Beyond Income, Beyond Averages, Beyond Today: Inequalities in Human Development in the 21st Century; Human Development Report 2019; United Nations Development Programme: New York, NY, USA, 2019. Available online: http://hdr.undp.org/sites/ default/files/hdr2019.pdf (accessed on 22 November 2021).

15. Frasquilho, D.; Matos, M.G.; Salonna, F.; Guerreiro, D.; Storti, C.C.; Gaspar, T.; Caldas-de-Almeida, J.M. Mental health outcomes in times of economic recession: A systematic literature review. BMC Public Health 2016, 16, 115. [CrossRef] [PubMed]

16. Haw, C.; Hawton, K.; Gunnell, D.; Platt, S. Economic recession and suicidal behaviour: Possible mechanisms and ameliorating factors. Int. J. Soc. Psychiatry 2015, 61, 73-81. [CrossRef] [PubMed]

17. Liu, J.; Modrek, S.; Sieverding, M. The mental health of youth and young adults during the transition to adulthood in Egypt. Demogr. Res. 2017, 36, 1721-1758. [CrossRef] [PubMed]

18. Hone, T.; Mirelman, A.J.; Rasella, D.; Paes-Sousa, R.; Barreto, M.L.; Rocha, R.; Millett, C. Effect of economic recession and impact of health and social protection expenditures on adult mortality: A longitudinal analysis of 5565 Brazilian municipalities. Lancet Glob. Health 2019, 7, e1575-e1583. [CrossRef]

19. Salahuddin, M.; Vink, N.; Ralph, N.; Gow, J. Effects of economic growth, foreign direct investment and internet use on child health outcomes: Empirical evidence from South Africa. Dev. Stud. Res. 2020, 7, 1-17. [CrossRef]

20. Costanza, R.; Hart, M.; Posner, S.; Talberth, J. Beyond GDP: The Need for New Measures of Progress; The Pardee Papers, No. 4.; Boston University: Boston, MA, USA, 2009. Available online: https:/ /www.bu.edu/pardee/files/documents/PP-004-GDP.pdf (accessed on 23 November 2021).

21. Hickel, J. The contradiction of the sustainable development goals: Growth versus ecology on a finite planet. Sustain. Dev. 2019, 27, 873-884. [CrossRef]

22. UNDP. Human Development Index (HDI). Available online: http://hdr.undp.org/en/content/human-development-index-hdi (accessed on 23 November 2021).

23. Sen, A.K. Commodities and Capabilities; Oxford University Press: Oxford, UK, 1984.

24. Sen, A.K. Capabilities, lists, and public reason: Continuing the conversation. Fem. Econ. 2004, 10, 77-80. [CrossRef]

25. Nussbaum, M. Creating Capabilities: The Human Development Approach; Harvard University Press: Cambridge, MA, USA, 2011.

26. Kabeer, N. Making Rights Work for the Poor: Nijera Kori and the Construction of 'Collective Capabilities' in Rural Bangladesh; Working Paper 200; Institute of Development Studies: Brighton, UK, 2003.

27. Scherer, L.; Behrens, P.; de Koning, A.; Heijungs, R.; Sprecher, B.; Tukker, A. Trade-offs between social and environmental Sustainable Development Goals. Environ. Sci. Policy 2018, 90, 65-72. [CrossRef]

28. Bali Swain, R.; Yang-Wallentin, F. Achieving sustainable development goals: Predicaments and strategies. Int. J. Sustain. Dev. 2020, 27, 96-106. [CrossRef]

29. Hickel, J. Quantifying national responsibility for climate breakdown: An equality-based attribution approach for carbon dioxide emissions in excess of the planetary boundary. Lancet Planet. Health 2020, 4, e399-e404. [CrossRef]

30. Islam, S.N.; Winkel, J. Climate Change and Social Inequality; DESA Working Paper No. 152; United Nations, Department of Economics and Social Affairs: New York, NY, USA, 2017.

31. Harrington, L.J.; Frame, D.J.; Fischer, E.M.; Hawkins, E.; Joshi, M.; Jones, C.D. Poorest countries experience earlier anthropogenic emergence of daily temperature extremes. Environ. Res. Lett. 2016, 11, 055007. [CrossRef]

32. OECD. Building Back Better: A Sustainable, Resilient Recovery after COVID-19; OECD Publishing: Paris, France, 2020. Available online: https: / / www.oecd.org/coronavirus/policy-responses/building-back-better-a-sustainable-resilient-recovery-after-covid19-52b869f5 (accessed on 23 November 2021).

33. ESCWA. Poverty in Lebanon: Solidarity is Vital to Address the Impact of Multiple Overlapping Shocks; Policy Brief 15; United Nations Economic and Social Commission for Western Asia: Beirut, Lebanon, 2020. Available online: https:/ /www.unescwa.org/sites/ default/files/pubs/pdf/covid-19-beirut-explosion-rising-poverty-en.pdf (accessed on 23 November 2021).

34. World Bank. Lebanon. World Bank. 2021. Available online: https://thedocs.worldbank.org/en/doc/a3d1489dafa646ee90f5a1 9abd950cab-0280012021/original/9-mpo-sm21-lebanon-lbn-kcm.pdf (accessed on 23 November 2021).

35. Karasapan, O.; Shah, S. Why Syrian Refugees in Lebanon Are a Crisis within a Crisis; Brookings. 2021. Available online: https: //www.brookings.edu/blog/future-development/2021/04/15/why-syrian-refugees-in-lebanon-are-a-crisis-within-a-crisis (accessed on 23 November 2021).

36. UNFPA. World Population Dashboard Lebanon; UNFPA: New York, NY, USA, 2021. Available online: https://www.unfpa.org/ data/world-population/LB (accessed on 1 February 2022).

37. World Bank. Unemployment, Youth Total (\% of Total Labor Force Ages 15-24) Lebanon; World Bank: Washington, DC, USA, 2019 Available online: https:/ / data.worldbank.org/indicator/SL.UEM.1524.ZS?locations=JO (accessed on 23 November 2021).

38. Chaaban, J.; Salti, N.; Ghattas, H.; Irani, A.; Ismail, T.; Batlouni, L. Survey on the Socioeconomic Status of Palestine Refugees in Lebanon 2015; The American University of Beirut (AUB) and the United Nations Relief and Works Agency for Palestine Refugees in the Near East (UNRWA): Beirut, Amman, 2016. 
39. World Bank. Labour Force Participation Rate for Ages 15-24, Total (\%) (Modeled ILO Estimate); World Bank: Washington, DC, USA, 2019. Available online: https://data.worldbank.org/indicator/SL.TLF.ACTI.1524.ZS (accessed on 1 February 2022).

40. Durgham, N.; Sly, L. Lebanon's National Electricity Grid Collapses. The Washington Post, 9 October 2021. Available online: https:/ / www.washingtonpost.com/world/middle_east/lebanon-power-beirut-electricity-collapse/2021/10/09/e2588e8 8-28fb-11ec-8739-5cb6aba30a30_story.html (accessed on 23 November 2021).

41. Chulov, M. Fraught Calm Follows Beirut's Worst Day of Sectarian Violence in Decade. The Guardian, 15 October 2021. Available online: https: / / www.theguardian.com/world/2021/oct/15/fraught-calm-follows-beiruts-worst-day-of-sectarian-violencein-decade (accessed on 23 November 2021).

42. International Association for Medical Assistance to Travellers (IAMAT). Lebanon General Health Risks: Air Pollution; IAMAT: Toronto, Canada, 2020.

43. Human Rights Watch. Lebanon: No Action to Enforce New Waste Law. Human Rights Watch, 18 October 2018. Available online: https:/ / www.hrw.org/news/2018/10/18/lebanon-no-action-enforce-new-waste-law (accessed on 23 November 2021).

44. Human Rights Watch. Lebanon: Huge Cost of Inaction in Trash Crisis. Human Rights Watch, 9 June 2020. Available online: https: / / www.hrw.org/news/2020/06/09/lebanon-huge-cost-inaction-trash-crisis\# (accessed on 23 November 2021).

45. USAID. Climate Change Risk Profile Lebanon. Fact Sheet; United States Agency for International Development: Washington, DC, USA, 2016. Available online: https:/ / www.climatelinks.org/sites/default/files/asset/document/2016_USAID_Climate\%20 Risk\%20Profile_Lebanon_2.pdf (accessed on 23 November 2021).

46. Hofste, R.W.; Reig, P.; Schleifer, L. 17 Countries, Home to One-Quarter of the World's Population, Face Extremely High Water Stress. Commentary; World Resources Institute: Washington, DC, USA, 2019. Available online: https://www.wri.org/insights/17 -countries-home-one-quarter-worlds-population-face-extremely-high-water-stress (accessed on 23 November 2021).

47. Taheripour, F.; Tyner, W.E.; Sajedinia, E.; Aguiar, A.; Chepeliev, M.; Corong, E.; de Lima, C.Z.; Haqiqi, I. Water in the Balance: The Economic Impacts of Climate Change and Water Scarcity in the Middle East; Technical Report; World Bank Group: Washington, DC, USA, 2020. Available online: https: / / openknowledge.worldbank.org/bitstream/handle/10986/34498/153087.pdf?sequence=1\& isAllowed $=y$ (accessed on 23 November 2021).

48. The Commonwealth. Global Youth Development Report; The Commonwealth: London, UK, 2020. Available online: https: //thecommonwealth.org/sites/default/files/inline/5023_V3_Book_lores_smaller.pdf (accessed on 23 November 2021).

49. World Population Review. Gini Coefficient By Country 2021. Available online: https://worldpopulationreview.com/countryrankings/gini-coefficient-by-country (accessed on 23 November 2021).

50. World Economic Forum. Global Gender Gap Report 2021. Insight Report March 2021; World Economic Forum: Geneva, Switzerland, 2021. Available online: http://www3.weforum.org/docs/WEF_GGGR_2021.pdf (accessed on 23 November 2021).

51. Government of Lebanon and the United Nations. Lebanon Crisis Response Plan 2017-2020; Government of Lebanon and the United Nations: Beirut, Lebanon, 2020.

52. UNHCR. Lebanon: January 2020. Fact Sheet. United Nations High Commissioner for Refugees: Geneva, Switzerland, 2020. Available online: https:/ / www.unhcr.org/lb/wp-content/uploads/sites/16/2020/02/UNHCR-Lebanon-Operational-Factsheet-January-2020-1.pdf (accessed on 23 November 2021).

53. UNHCR. Syria Regional Refugee Response, Lebanon; United Nations High Commissioner for Refugees: Geneva, Switzerland, 2021 Available online: https:/ / data2.unhcr.org/en/situations/syria/location/71 (accessed on 1 February 2022).

54. Jaafar, H.; Ahmad, F.; Holtmeier, L.; King-Okumu, C. Refugees, water balance, and water stress: Lessons learned from Lebanon. Ambiology 2020, 49, 1179-1193. [CrossRef] [PubMed]

55. Refaat, M.M.; Mohanna, K. Syrian refugees in Lebanon: Facts and solutions. Lancet 2013, 382, 763-764. [CrossRef]

56. Jones, N.; Pincock, K.; Abu Hamad, B. (Eds.) Adolescents in Humanitarian Crisis: Displacement, Gender and Social Inequalities; Routledge: Oxford, UK, 2021.

57. UNHCR; UNICEF; WFP. Vulnerability Assessment of Syrian Refugees in Lebanon. 2021. Available online: https://data.unhcr. org/en/documents/details/85002 (accessed on 23 November 2021).

58. UNHCR Lebanon. Shelter. UNHCR Lebanon. 2021. Available online: https://www.unhcr.org/lb/shelter (accessed on 23 November 2021).

59. Human Rights Watch. Lebanon: Dire Conditions for Syrian Refugees in Border Town. Human Rights Watch, 19 January 2021. Available online: https://www.hrw.org/news/2021/01/19/lebanon-dire-conditions-syrian-refugees-border-town (accessed on 23 November 2021).

60. ACTED. Overcrowded and Dilapidated Collective Shelters in Lebanon. ACTED. 2014. Available online: https://reliefweb.int/ report/lebanon/overcrowded-and-dilapidated-collective-shelters-lebanon (accessed on 23 November 2021).

61. UNRWA. Where We Work. United Nations Relief and Works Agency for Palestine Refugees in the Near East, Amman Jordan and Gaza Palestinian Authority. Available online: https:/ /www.unrwa.org/where-we-work/lebanon (accessed on 1 February 2022).

62. UNRWA; UNICEF. Youth Strategic Framework for Palestine Refugees in Lebanon United Nations Relief and Works Agency for Palestine Refugees in the Near East; Amman, Jordan and Gaza Palestinian Authority: Beirut, Lebanon, 2018.

63. Lebanese Palestinian Dialogue Committee; Central Administration of Statistics (CAS). Palestinian Central Bureau of Statistics (PCBS). In Population and Housing Census in Palestinian Camps and Gatherings in Lebanon 2017; PCBS/CAS: Beirut, Lebanon, 2018.

64. Anera. Clashes in Ein El Hilweh Leave Refugee Families Displaced Again. Anera, 2020. Available online: https://www.anera. org/stories/\%20clashes-in-ein-el-hilweh-leave-refugee-families-displaced (accessed on 23 November 2021). 
65. Ullrich, L.; Sharar, S.A. Nothing and Everything to Lose: Results from a Qualitative WhatsApp Survey of Palestinian Camps and Gatherings in Lebanon; United Nations Development Programme: New York, NY, USA, 2020. Available online: https://www.lb.undp.org/ content/dam/lebanon/docs/Governance/Publications/UNDP\%20WhatsApp\%20Survey\%20Report_Final.pdf (accessed on 23 November 2021).

66. UNICEF and International Medical Corps (IMC). Mental Health/Psychosocial and Child Protection for Syrian Adolescent Refugees; UNICEF: New York, NY, USA, 2014.

67. GAGE Consortium; Gender and Adolescence. Why Understanding Adolescent Capabilities, Change Strategies and Contexts Matters, 2nd ed.; Gender and Adolescence, Global Evidence: London, UK, 2019.

68. Honwana, A. Youth, Waithood, and Protest Movements in Africa. Lecture at the 5th European Conference on African Studies: African Dynamics in a Multipolar World, Lisbon, Portugal, 28 June 2013. Available online: http://hdl.handle.net/10071/7528 (accessed on 23 November 2021).

69. Albawaba Business. Lebanon Bans Diesel-Fueled Vehicles. 2002. Available online: https://www.albawaba.com/business/ lebanon-bans-diesel-fueled-vehicles (accessed on 1 February 2022).

70. Ministry of Environment/UNDP/Global Environment Facility (GEF). Economic Costs to Lebanon from Climate Change: A First Look; UNDP Lebanon: Beirut, Lebanon, 2015. Available online: https:/ / climatechange.moe.gov.lb/viewfile.aspx?id=228 (accessed on 23 November 2021).

71. Waha, K.; Krummenauer, L.; Adams, S.; Aich, V.; Baarsch, F.; Coumou, D. Climate change impacts in the Middle East and Northern Africa (MENA) region and their implications for vulnerable population groups. Reg. Environ. Chang. 2017, 17, 1623-1638. [CrossRef]

72. Government of Lebanon. Lebanon's Nationally Determined Contribution; Updated 2020 Version; Government of Lebanon: Beirut, Lebanon, 2020. Available online: https:/ / climatechange.moe.gov.lb/viewfile.aspx?id=319 (accessed on 23 November 2021).

73. Podesta, J. The Climate Crisis, Migration, and Refugees; Brookings: Washington, DC, USA, 2019.

74. Richards, J.; Bradshaw, S. Uprooted by climate change. In Responding to the Growing Risk of Displacement; Oxfam: Oxford, UK, 2017.

75. Viner, R.M.; Ross, D.; Hardy, R.; Kuh, D.; Power, C.; Johnson, A. Life course epidemiology: Recognising the importance of adolescence. J. Epidemiol. Community Health 2015, 69, 719-720. [CrossRef] [PubMed]

76. Zhang, Y.; Mavoa, S.; Zhao, J.; Raphael, D.; Smith, M. The association between green space and adolescents' mental well-being: A systematic review. Int. J. Environ. 2020, 17, 6640. [CrossRef]

77. Jarvis, I.; Davis, Z.; Sbihi, H.; Brauer, M.; Czekajlo, A.; Davies, H.W.; Gergel, S.E.; Guhn, M.; Jerrett, M.; Koehoorn, M.; et al Assessing the association between lifetime exposure to greenspace and early childhood development and the mediation effects of air pollution and noise in Canada: A population-based birth cohort study. Lancet Planet. Health 2021, 5, e709-e717. [CrossRef]

78. Engemann, K.; Pedersen, C.B.; Arge, L.; Tsirogiannis, C.; Mortensen, P.B.; Svenning, J.-C. Residential green space in childhood is associated with lower risk of psychiatric disorders from adolescence into adulthood. Proc. Natl. Acad. Sci. USA 2019, 116, 5188-5193. [CrossRef] [PubMed]

79. Lin, W.-H.; Pan, W.-C.; Yi, C.-C. 'Happiness in the air?' The effects of air pollution on adolescent happiness. BMC Public Health 2019, 19, 795. [CrossRef] [PubMed]

80. Tainio, M.; Jovanovic Andersen, Z.; Nieuwenhuijsen, M.J.; Hu, L.; de Nazelle, A.; An, R.; Garcia, L.M.T.; Goenka, S.; ZapataDiomedi, B.; Bull, F.; et al. Air pollution, physical activity and health: A mapping review of the evidence. Environ. Int. 2021, 147, 105954. [CrossRef] [PubMed]

81. Oxford Analytica. Jordan's Coming Climate Crisis Will Hit Youth Hard; Expert Briefings: Oxford, UK, 2021.

82. Frakes, N. Lebanon's Air Pollution Nears Alarming Level. Al-Monitor, 23 July 2019. Available online: https://www.almonitor.com/originals/2019/07/lebanon-budget-cuts-environment-air-monitoring-pollution.html\#ixzz7CP4ovrx7 (accessed on 22 November 2021). 